\title{
Role of soluble and membrane-bound dipeptidyl peptidase-4 in diabetic nephropathy
}

\author{
Ahmed A Hasan1,2 and Berthold Hocher1,3,4 \\ IInstitute of Nutritional Science, University of Potsdam, Potsdam, Germany \\ 2Department of Biochemistry, Faculty of Pharmacy, Zagazig University, Zagazig, Egypt \\ ${ }^{3}$ Institut für Laboriatorumsmedizin IFLb, Berlin, Germany \\ ${ }^{4}$ Departments of Embryology and Nephrology, Basic Medical College, Jinan University, Guangzhou, China
}

Correspondence should be addressed to B Hocher

Email

hocher@uni-potsdam.de

\begin{abstract}
Diabetic nephropathy is one of the most frequent, devastating and costly complications of diabetes. The available therapeutic approaches are limited. Dipeptidyl peptidase type 4 (DPP-4) inhibitors represent a new class of glucose-lowering drugs that might also have reno-protective properties. DPP-4 exists in two forms: a plasma membranebound form and a soluble form, and can exert many biological actions mainly through its peptidase activity and interaction with extracellular matrix components. The kidneys have the highest DPP-4 expression level in mammalians. DPP-4 expression and urinary activity are up-regulated in diabetic nephropathy, highlighting its role as a potential target to manage diabetic nephropathy. Preclinical animal studies and some clinical data suggest that DPP-4 inhibitors decrease the progression of diabetic nephropathy in a blood pressure- and glucose-independent manner. Many studies reported that these reno-protective effects could be due to increased half-life of DPP-4 substrates such as glucagon-like peptide-1 (GLP-1) and stromal derived factor-1 alpha (SDF-1a). However, the underlying mechanisms are far from being completely understood and clearly need further investigations.
\end{abstract}
Key Words
- DPP-4
- diabetic nephropathy
- DPP-4 inhibitors
- GLP-1 and SDF-1a

Journal of Molecular

Endocrinology

(2017) 59, R1-R10

\section{Introduction}

According to the global report on diabetes issued by the World Health Organization, the worldwide diabetes prevalence, the vast majority of these cases are attributed to type 2 diabetes, has increased to reach $8.5 \%$ of the population over 18 years of age in 2014. Type 2 diabetes is associated with many macrovascular and microvascular complications and known to be a major cause underlying kidney failure. Recently, new classes of drugs have been approved for the treatment of type 2 diabetes and extensive research is going on to investigate potential beneficial effects, beside their glucose-lowering effects, on various diabetic complications such as diabetic nephropathy. These therapies include glucagon-like peptide 1 (GLP-1) agonists, dipeptidyl peptidase type 4 (DPP-4) inhibitors and sodium-glucose cotransporter (SGLT2) inhibitors (Ingelfinger \& Rosen 2016). The aim of this review is to summarize the up-to-date literature on DPP-4 in the setting of diabetic nephropathy and to discuss DPP-4 as a potential target for the management of diabetic nephropathy. 


\section{Discovery, molecular biology and renal expression of DPP-4}

DPP-4 was first discovered by (Hopsu-Havu \& Glenner 1966) as they identified it as a new enzyme in rat liver homogenate and rat kidney histological sections which is capable of hydrolysing glycyl-prolyl-B-naphthylamide, a synthesized chromogenic substrate. Later, further research revealed that the mouse thymocyte-activating molecule and CD26 antigen on T-lymphocyte are actually a plasma membrane-bound form of DPP-4 (Ulmer et al. 1990, Vivier et al. 1991). There are two forms of DPP-4, the plasma membrane-anchored form and the soluble form. The pleiotropic biological actions of DPP-4 are mainly attributed to its protease activity, degrading many substrates with different biological effects, interaction with extracellular matrix components, such as collagen and fibronectin, and acting as cell surface co-receptor affecting intracellular signal transduction. DPP-4 was increasingly brought into the spotlight after the approval of the DPP-4 inhibitors for treating type 2 diabetes (Mulvihill \& Drucker 2014).

Regarding the enzymatic activity, DPP-4 is a specific serine peptidase which can cleave off N-terminal dipeptides provided that the penultimate amino acid is proline, hydroxyproline or alanine. Due to the high similarity between the parent peptide and the DPP-4cleaved peptide, they differ usually only in two amino acids, very sensitive assays are required to differentiate between both forms. It is also challenging to compare the biological activity of the parent peptide versus the DPP4-cleaved peptide which is not necessarily less active or inactive (Mulvihill \& Drucker 2014).

DPP-4 is expressed in many tissues including the kidney. Using quantitative real-time PCR and Western blot, DPP-4 mRNA and protein were detected in glomerular mesangial cells and preglomerular microvascular smooth muscle cells from spontaneously hypertensive and normotensive rats (Jackson et al. 2012). DPP-4 expression was also reported in glomerular podocytes and proximal tubules of the rat kidney (Hartel et al. 1988, Kettmann et al. 1992). Furthermore, DPP-4 expression was identified at the brush border membrane of human proximal tubular cells (Stange et al. 1996). Moreover, induction of diabetes, using streptozotocin plus high fat diet, up-regulated DPP-4 expression in the rat kidneys, primarily in renal tubular cells (Yang et al. 2007). In addition, our group described the expression of DPP-4 in glomerular podocytes and proximal tubules of the kidneys of normal and diabetic mice. Interestingly, immunofluorescence staining detected the expression of DPP-4 in the glomerular podocytes of patients with diabetic nephropathy, but not in healthy human kidneys (Sharkovska et al. 2014). The renal expression of DPP-4 is summarized in Fig. 1. Interestingly, Wang and coworkers (Wang et al. 2014) found that rat kidney extracts showed the highest DPP-4 activity; however, plasma DPP-4 activity did not decrease after kidney transplantation from a DPP-4-deficient rat into a wild-type one indicating that the kidney is not the main source of soluble DPP-4 under normal healthy conditions. In addition, it was reported that urinary DPP-4 activity was significantly higher in type 2 diabetic patients with microalbuminuria, an early sign of diabetic nephropathy, compared to healthy individuals (Mitic et al. 2008). These observations highlight a potential role of DPP-4 in the development of diabetic nephropathy (von Websky et al. 2014).

\section{DPP-4 inhibition in animal models of diabetic nephropathy}

DPP-4 inhibitors were tested in many animal models of chronic and acute kidney injury. In this section, we will focus on the studies investigating the renal effects of DPP-4 inhibitors in animal models of diabetic nephropathy. Sitagliptin, the first approved DPP-4 inhibitor, was tested in Zucker diabetic fatty (ZDF) rats as a model of type 2 diabetic nephropathy to investigate its effects on metabolic profile and kidney injury (Mega et al. 2011). Sitagliptin administration led to improved kidney function, decreased renal oxidative stress and abolished renal damage as illustrated by histological examination. The reno-protective effects of sitagliptin in this study could be at least partly attributed to its ability to ameliorate hyperglycaemia and serum triglycerides. Another study showed that vildagliptin could counteract kidney injury in terms of albuminuria, creatinine clearance and histological findings in streptozotocin (STZ)-induced diabetic rats (Liu et al. 2012). The authors suggested that the activation of GLP-1 receptor, modulation of cAMP, decreased oxidative stress and downregulation of TGFB1 might be involved in the reno-protective pathways of vildagliptin. Moreover, Kodera and coworkers (Kodera et al. 2014) reported that DPP-4 inhibition using PKF275-055 improved kidney parameters in STZ-induced diabetic rats through inhibition of inflammatory events as macrophage infiltration and suppression of nuclear factor-кB.

The reno-protective effects of DPP-4 inhibition in diabetic nephropathy could be a consequence of the antidiabetic actions of DPP-4 inhibitors. However,

Published by Bioscientifica Ltd. 
Renal expression of DPP-4

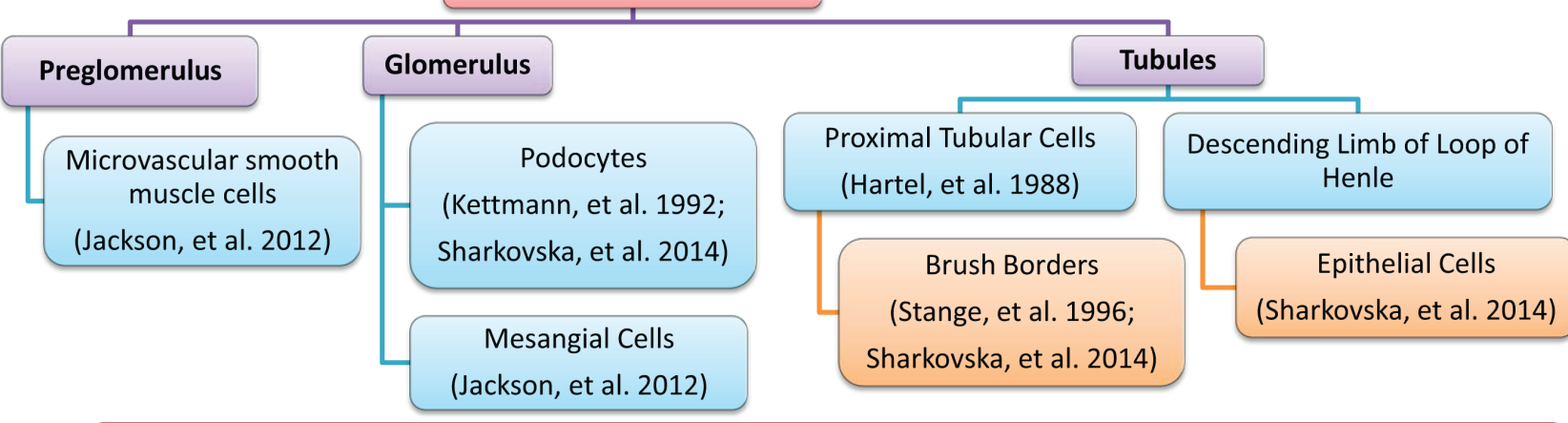

DPP-4 expression was detected in the glomerular podocytes of patients with diabetic nephropathy, but not in healthy human kidneys (Sharkovska, et al. 2014)
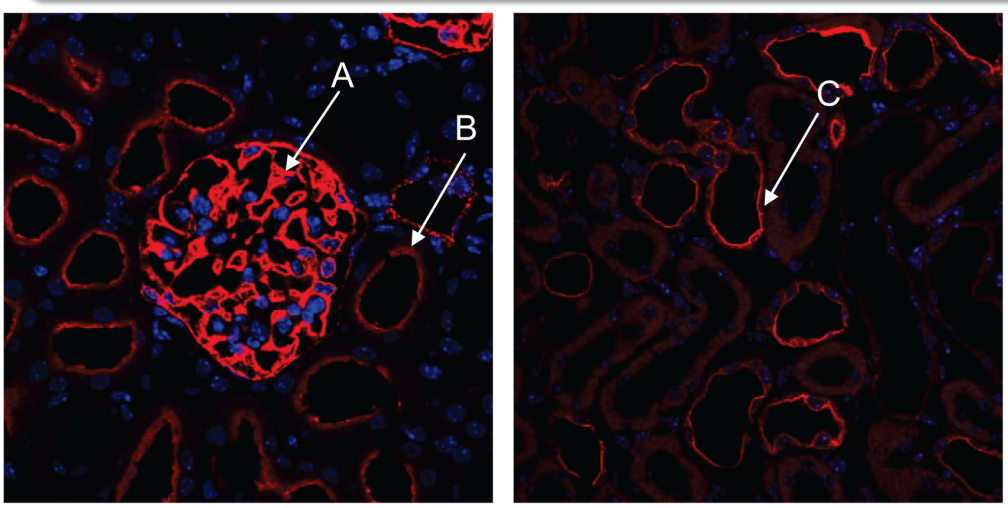
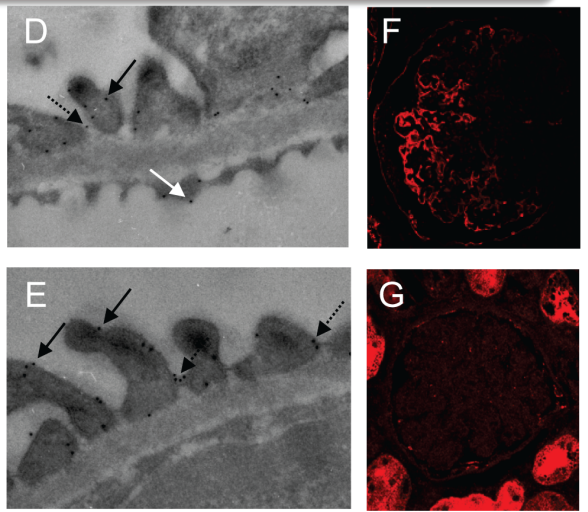

\section{Figure 1}

DPP-4 expression in the kidney. DPP-4 (red) expression was detected in glomerular podocytes (A), the brush borders of the proximal tubular cells (B) and epithelia of descending limb of Henle's loop (C) (immunofluorescence staining). DPP-4 (black dots) expression was detected (D and E) in the membrane of the podocyte foot process (black arrows), fenestrated endothelium (white arrows) and slit diaphragm (dotted arrow) (Immunogold electron microscopy). DPP-4 (red) expression was detected in glomerular podocytes of patients with diabetic nephropathy (F), but not in healthy human kidneys (G) (Immunofluorescence staining). The microscopic photos are reproduced, with permission, from Sharkovska Y, Reichetzeder C, Alter M, Tsuprykov O, Bachmann S, Secher T, Klein T \& Hocher B, 'Blood pressure and glucose independent renoprotective effects of dipeptidyl peptidase-4 inhibition in a mouse model of type-2 diabetic nephropathy', Journal of Hypertension, volume 32, pages 2211-2223, http://dx.doi.org/10.1097/HJH.0000000000000328. Copyright 2014, Wolters Kluwer Health, Inc.

Sharkovska and coworkers (Sharkovska et al. 2014) found that in $d b / d b$ mice, a model of type 2 diabetes, neither glucose metabolism nor blood pressure were affected by linagliptin treatment, despite that linagliptin was able to decrease the progression of diabetic kidney damage. These findings indicated that the renal beneficial actions of DPP-4 inhibition are independent on blood pressure and glucose metabolism. In addition, the DPP-4 inhibitor linagliptin reduced advanced glycation end products (AGEs) levels; the gene expression of their receptor (RAGE); 8-hydroxy2 -deoxyguanosine, a marker of oxidative stress; and lymphocyte infiltration and intercellular adhesion molecule-1 (ICAM-1) mRNA levels, a proinflammatory peptide in the kidney of STZ-diabetic rats. Interestingly, these effects were not accompanied by improvement of hyperglycaemia (Nakashima et al. 2014). Furthermore,
DPP-4 deficiency led to similar findings in STZ-induced diabetic DPP-4 deficient rats, indicating that both DPP-4 inhibition and DPP-4 deficiency could be reno-protective by obstructing the AGE-RAGE axis (Matsui et al. 2015).

Also, DPP-4 inhibition using linagliptin led to decreased progression of diabetic nephropathy in STZinduced diabetic CD-1 mice as demonstrated by measuring plasma cystatin C, urinary albumin-to-creatinine ratio (UACR) and histopathological examinations of the kidney. Linagliptin abolished endothelial levels of DPP-4 and integrin B1, a transmembrane receptor which bridges cellcell and cell-extracellular matrix components interactions leading to decreased renal fibrosis through inhibition of TGFB2-induced-endothelial-to-mesenchymal transition. These anti-fibrotic effects were mediated via microRNA 29 induction (Kanasaki et al. 2014, Shi et al. 2015). 
Furthermore, gemigliptin normalized albuminuria, mesangial expansion, oxidative damage and podocyte apoptosis in the kidneys of $d b / d b$ mice (Jung et al. 2015, Moon et al. 2016).

An interesting recent study revealed that linagliptin suppressed albuminuria in $G l p 1 r^{+/+}$diabetic-prone Akita mice but not in Glp1r--diabetic-prone Akita mice, however, linagliptin was able to normalize the renal histopathology in both strains. These results showed that DPP-4 inhibition could have reno-protective effects through glucagonlike peptide-1 receptor (GLP-1R) and also through other substrates such as stromal derived factor-1 alpha (SDF-1a) independent of GLP-1R (Takashima et al. 2016).

The animal studies, which investigated DPP-4 inhibition in animal models of diabetic nephropathy, are summarized in Table 1 and the renal effects of DPP- 4 inhibitors in diabetic nephropathy and the proposed underlying mechanisms are outlined in Fig. 2. In conclusion, there are obviously different pathways involved in the reno-protective properties of DPP-4 inhibitors. This is most likely attributed to the fact that DPP-4 inhibition has a lot of potential peptide targets that might be involved in the pathogenesis of diabetic nephropathy. This is a fundamental difference from a pharmacological point of view to classical single target drugs such as angiotensin II receptor blockers (ARBs) which just block the angiotensin II receptor.

The finding that DPP-4 inhibitors have beneficial renal effects in animal models of diabetic nephropathy independent of blood pressure and plasma glucose encouraged stimulated research groups, including ours, to study DPP-4 inhibitors in models of non-diabetic nephropathy. DPP-4 inhibitors were found to have renal beneficial effects in animal models of non-diabetic nephropathy such as 5/6 nephrectomy (Tsuprykov et al. 2016)

Table 1 DPP-4 inhibitors in animal models of diabetic nephropathy.

Animal model

Zucker diabetic fatty (ZDF) rats

DPP-4 inhibitor

Sitagliptin

Streptozotocin-induced

diabetic rats

Vildagliptin

Streptozotocin-induced Linagliptin diabetic eNOS knockout mice

Streptozotocin-induced diabetic rats

PKF275-055

Diabetic $d b / d b$ mice

Linagliptin

Streptozotocin-induced diabetic rats

Streptozotocin-induced diabetic DPP-4 deficient rats

Streptozotocin-induced diabetic CD-1 mice

Diabetic $d b / d b$ mice

Glp1r+/+ and Glp1r-1- diabetic- Linagliptin prone Akita mice
Gemigliptin

Linagliptin

Genetic DPP-4 deficiency - Decreased glomerular area

- Decreased urinary excretion of albumin

- Reduced plasma cystatin C levels and UACR

- Ameliorated kidney fibrosis, glomerular size and mesangial area

- Suppressed albuminuria

- Decreased mesangial expansion

- Suppressed podocyte apoptosis

- Reduced oxidative damage

- Suppressed albuminuria (only in Glp $1 r^{+/+}$diabetic-prone Akita mice)

- Suppressed glomerulosclerosis, periglomerular fibrosis, podocyte loss, and renal oxidative stress
Reference

Mega et al. (2011)

Liu et al. (2012)

- Improved creatinine clearance

interstitial expansion,

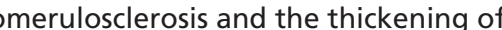

- Reduced glomerulosclerosis

Alter et al. (2012)

- Reduced albuminuria (only in combination

mesangial matrix expansion

- Reduced albuminuria

Nakashima et al. (2014)

Matsui et al. (2015)

Kanasaki et al. (2014),

Shi et al. (2015)

Jung et al. (2015),

Moon et al. (2016)

Takashima et al. (2016) http://jme.endocrinology-journals.org DOI: 10.1530/JME-17-0005
๑ 2017 Society for Endocrinology Printed in Great Britain
Published by Bioscientifica Ltd 
Renal effects in diabetic nephropathy - Improved kidney function :

$\downarrow$ BUN, $\downarrow$ UACR, $\uparrow$ creatinine clearance and $\downarrow$ plasma cystatin $C$

- Corrected renal histopathology :

$\downarrow$ Interstitial fibrosis, $\downarrow$ glomerulosclerosis, $\downarrow$ glomerular hypertrophy and $\downarrow$ podocyte loss

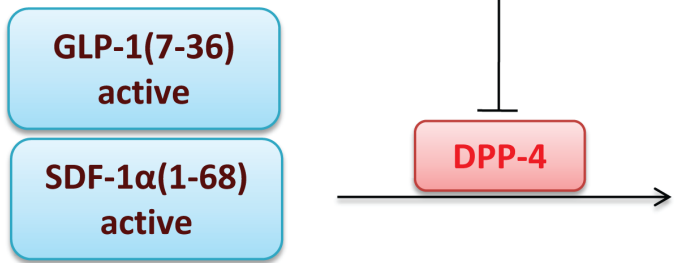

Other substrates e.g. GIP, BNP, substance $P$, peptide YY and NPY

\section{Cleaved substrates which are inactive,} less active or with modified activity

\section{Figure 2}

DPP-4, its substrates and DPP-4 inhibitors in diabetic nephropathy. BUN, blood urea nitrogen; UACR, urinary albumin to creatinine ratio; MDA, malondialdehyde; 8-OHdG, 8-hydroxy-2'-deoxyguanosine; ICAM-1, intercellular adhesion molecule-1; TGF $\beta$, transforming growth factor beta; $\mathrm{NF}_{\mathrm{KB}}$, nuclear factor kappa B; AGE, advanced glycation endproducts; RAGE, receptor of AGE; EndMT, endothelial-to-mesenchymal transition; GLP-1, glucagon like peptide-1; SDF-1a, stromal derived factor-1 alpha; GIP, glucose dependent insulinotropic polypeptide; BNP, brain natriuretic peptide; NPY, neuropeptide Y.

2-kidney-1-clip hypertension (Chaykovska et al. 2013), tacrolimus-induced kidney injury (Lim et al. 2015), rat Thy-1 glomerulonephritis model (Higashijima et al. 2015) and unilateral ureteral obstruction (Min et al. 2014).

\section{Clinical data on DPP-4 inhibitors in diabetic nephropathy}

There are few clinical studies which investigated the renal effects of DPP-4 inhibitors in diabetic nephropathy. A pooled analysis of four clinical studies reported that linagliptin on top of inhibitors of the renin-angiotensinaldosterone system abolished UACR in type 2 diabetic subjects with prevalent albuminuria after 24 weeks of treatment and this effect was independent of the changes of HbA1c and systolic blood pressure (Groop et al. 2013). Another clinical study (Hattori 2011) revealed that 6 months of sitagliptin treatment lowered systolic and diastolic blood pressure, blood glucose, C-reactive protein, soluble vascular cell adhesion molecule 1 and UACR in patients with type 2 diabetes. In agreement with these findings, Sakata and coworkers (Sakata et al. 2013) demonstrated that fasting blood glucose, HbAlc, circulating soluble form of RAGE and UACR were decreased after treatment with alogliptin for twelve weeks in Japanese patients with type 2 diabetes. In addition, type 2 diabetic patients, treated with saxagliptin and followed for a median of 2.1 years, were significantly more likely than patients treated with placebo, to have a lower UACR (Scirica et al. 2013). Moreover, Fujita and coworkers (Fujita et al. 2014b) performed a cross-over study to investigate the effects of sitagliptin and alogliptin in twelve patients, with diabetic nephropathy, taking ARBs. The treatment regimen consists of three periods; sitagliptin for 4 weeks, alogliptin for 4 weeks and again sitagliptin for 4 weeks. The switch from sitagliptin to alogliptin, a stronger DPP-4 inhibitor, was associated with declined UACR and oxidative stress and elevated urinary cAMP and plasma SDF-1a.

In a recent clinical study, Goldshtein and coworkers (Goldshtein et al. 2016) compared the change in UACR in type 2 diabetic patients with albuminuria receiving sitagliptin to those receiving sulphonylurea as add-on to metformin monotherapy. Both sitagliptin and sulphonylurea decreased albuminuria as an add-on therapy to metformin, however, sitagliptin resulted in greater reductions in albuminuria independent of glycemic control compared to sulphonylurea.

Published by Bioscientifica Ltd. 
Interestingly, a randomized, double-blind and placebocontrolled clinical study (MARLINA-T2D TM) (Groop et al. 2015) to evaluate the glycemic and renal efficacy of linagliptin treatment for 24 weeks in patients with diabetic nephropathy on top of current treatment with angiotensinconverting-enzyme inhibitor (ACE-I) or ARBs was recently completed. No hemodynamic changes were induced after adding linagliptin to stable ACE-I or ARBs treatment regimens. Furthermore, linagliptin was shown to improve glycemic control without affecting UACR significantly (Cooper et al. 2016, Groop et al. 2016). This study was most likely too short to demonstrate a decrease in the slope of glomerular filtration rate (GFR). The potential beneficial renal effects of linagliptin are currently challenged in an ongoing long-term clinical trial (CARMELINA).

\section{Membrane-bound DPP-4}

The two main pathways through which DPP-4 inhibition can ameliorate diabetic nephropathy are increased half-life of DPP-4 substrates, which have many biological actions, and inhibition of membrane-bound form of DPP-4 in the kidney, which could interact with extracellular matrix components and regulate intracellular signal transduction (Fig. 3). Panchapakesan and Pollock (2014), and Zeisberg and Zeisberg (2015) suggested a mechanism for the antifibrotic activity of linagliptin in the kidney. The membrane-bound
DPP-4 interacts minimally with the cation-independent mannose 6-phosphate receptor (CIM6PR) and integrin B1 in normoglycemic conditions, but these interactions increase in hyperglycemic conditions leading to the activation of TGFB pathway and fibrosis. Linagliptin can block these interactions by binding and inhibiting the membranebound DPP-4. More research is needed to define the renoprotective mechanisms of DPP-4 inhibitors and this would help to discover novel pathways and targets through which diabetic nephropathy could be managed.

\section{Distinction between soluble and membrane-bound DPP-4}

The only structural difference between the soluble and membrane-bound DPP-4 is that the soluble form lacks the cytoplasmic, transmembrane and flexible domains, whereas the two forms share all the other domains including the catalytic site (Mulvihill \& Drucker 2014). Therefore, theoretically, any DPP-4 inhibitor can inhibit both soluble and membrane-bound DPP-4. Another important consideration is the volume of distribution of different DPP-4 inhibitors. We can hypothesize that DPP-4 inhibitors with greater volume of distribution, with a higher tissue-toblood ratio, such as linagliptin could inhibit the membranebound DPP-4 more than the DPP-4 inhibitors with lower volume of distribution such as sitagliptin. In line with this

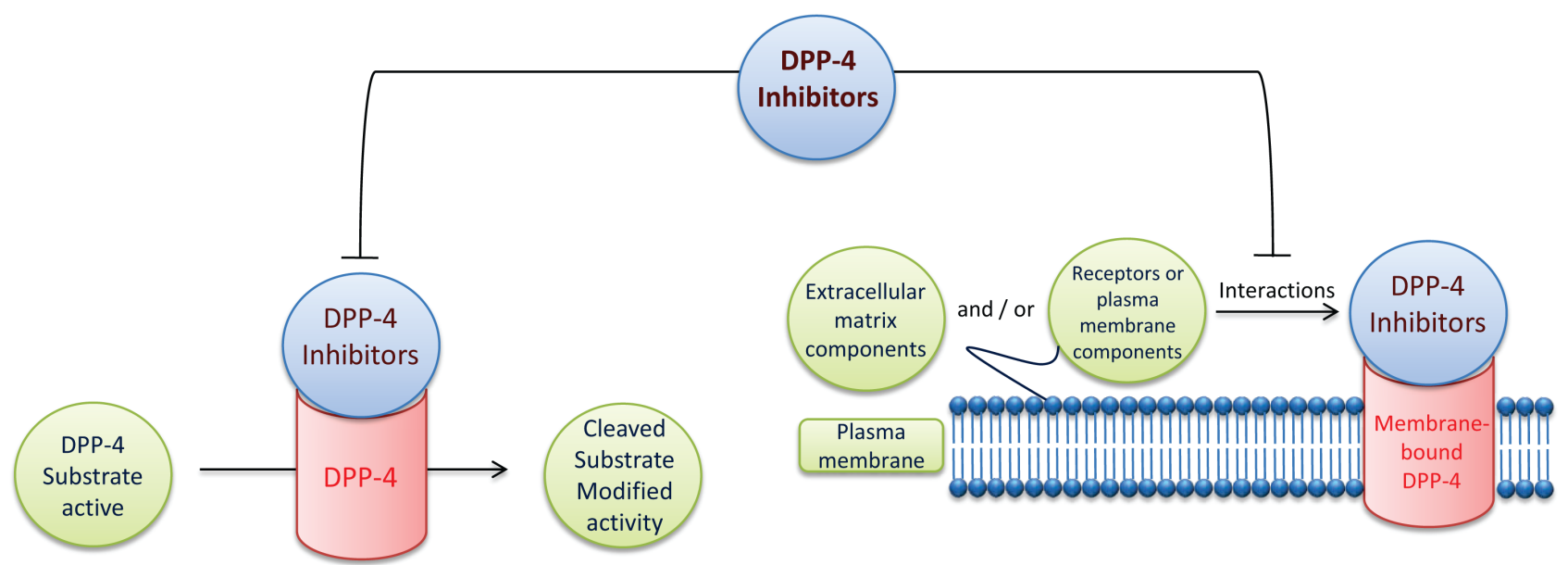

Inhibition of degradation of DPP-4 substrates (e.g. GLP-1, SDF-1, BNP, NPY, ...etc), thus increasing their half-lives

Blocking of interactions of membrane-bound DPP-4 with extracellular matrix components, receptors and/or plasma membrane components (e.g. CIM6PR and integrin B1), thus ameliorating extracellular matrix and intracellular signal transduction

Figure 3

Pathways of the biological actions of DPP-4 inhibitors. GLP-1, glucagon like peptide-1; SDF-1a, stromal derived factor-1 alpha; BNP, brain natriuretic peptide; NPY, natriuretic peptide Y; CIM6PR, cation-independent mannose 6-phosphate receptor.

http://jme.endocrinology-journals.org DOI: 10.1530/JME-17-0005
(C) 2017 Society for Endocrinology Printed in Great Britain
Published by Bioscientifica Ltd. 
hypothesis, renal DPP-4 activity was significantly inhibited by linagliptin, while neither sitagliptin nor vildagliptin could elicit similar effect in a head-to-head comparison of the three compounds in a rat model of renal ischaemiareperfusion injury (Reichetzeder et al. 2017). In this regard, more studies are needed to investigate the pharmacological differences between soluble and membrane-bound DPP-4 deeply and compare the available DPP-4 inhibitors regarding their ability to inhibit different forms of DPP-4 in the setting of diabetic nephropathy.

\section{DPP-4 substrates in diabetic nephropathy}

DPP-4 can cleave many substrates with many biological actions. In this section, we will review GLP-1 and SDF-1a, the most studied substrates of DPP-4 with potential roles in diabetic nephropathy.

\section{GLP-1}

GLP-1 is an incretin which is secreted from intestinal L-cells in response to oral glucose load and can stimulate insulin secretion from pancreatic B cells and inhibit glucagon release. GLP-1 is secreted in active form, GLP-1 (7-36), and rapidly degraded by DPP-4 into GLP-1 (9-36), rendering the active GLP-1 a very short half-life. Thus, two pharmacological approaches appeared to get use of the antihyperglycemic effects of GLP-1, first GLP-1 analogues such as exenatide and liraglutide which can resist degradation by DPP-4, and second DPP-4 inhibitors, the gliptins family, which can block the DPP-4-induced breakdown of GLP-1 (7-36) and other substrates. Both classes of drugs include approved drugs for the treatment of type 2 diabetes (von Websky et al. 2014). GLP-1R is expressed in the kidney in many species but the present literature on its exact localization needs more investigation due to doubts about the specificity and sensitivity of the available GLP-1R antibodies (Pyke \& Knudsen 2013). In a study by Schlatter et al. (2007), GLP-1R was reported to be expressed in porcine renal proximal tubules at mRNA and protein levels. Moreover, GLP-1R expression was predominately detected in proximal tubular cells after staining of human and pig renal cortex. Using real-time RT-PCR in rat kidneys, (Crajoinas et al. 2011) revealed that GLP-1 receptor-mRNA expression was only detected in the glomerulus and proximal convoluted tubule. An interesting study revealed that Glp1r mRNA was localized only in glomerular capillary walls and renal blood vessels and not in tubules using in situ hybridization and these findings were confirmed by PCR (Fujita et al. 2014a).
The effects of GLP-1 in diabetic nephropathy have been investigated in many studies using degradationresistant GLP-1R agonists. It was shown that exendin-4, a GLP-1 analogue, prevented glomerular endothelial dysfunction in the kidneys of STZ-diabetic mice by inhibiting the signalling pathway of angiotensin II and these renal protective effects were counteracted by protein kinase $\mathrm{C}-\mathrm{B}$ (PKCB) activation and reduced expression of GLP-1R using GLP-1R small interfering RNA in the glomerular endothelial cells (Mima et al. 2012). Exendin-4 treatment was also reported to delay the progression of diabetic nephropathy in $d b / d b$ mice as indicated by decreased urinary albumin excretion and improved renal histopathology. These effects were accompanied by downregulation of TGFB1 expression, decreased collagen type IV accumulation, suppressed inflammation, reduced apoptosis and lower oxidative stress (Park et al. 2007). In alignment with these findings, many other studies also revealed renal beneficial effects of GLP-1 analogues in animal models of diabetic nephropathy suggesting many mechanisms behind these effects such as cAMPprotein kinase A pathway activation, inhibition of renal $\mathrm{NAD}(\mathrm{P}) \mathrm{H}$ oxidases (Hendarto et al. 2012, Fujita et al. 2014a), downregulation of AGE-induced protein arginine methyltranferase-1 expression(Ojima etal.2013), decreased ICAM-1 production, reduced release of proinflammatory cytokines from macrophages (Kodera et al. 2011) and up-regulation of ATP-binding cassette transporter A1 (ABCA1) in glomerular endothelial cells, which promoted cholesterol efflux from cells and blocked inflammatory responses (Yin et al. 2016). Moreover, the natriuretic and diuretic effects of GLP-1 analogues and DPP-4 inhibitors through interaction with $\mathrm{Na}^{+} / \mathrm{H}^{+}$exchanger isoform 3 could play a role regarding their reno-protective effects. Interestingly, Rieg and coworkers (Rieg et al. 2012) reported that the natriuretic effect of exendin-4, but not alogliptin, was absent in Glp1r- mice, indicating that the natriuretic effect due to DPP-4 inhibition was not only mediated by GLP-1R activation. Moreover, exendin-4 showed antifibrotic effects in human mesangial cells cultured in a high glucose medium through attenuated expression of TGFB1 and connective tissue growth factor (CTGF) and activation of adenylate cyclase (Li et al. 2012).

In addition, literature provides some clinical data regarding renal effects of GLP-1 analogues. In a small study including twenty-three type 2 diabetic patients with diabetic nephropathy, treatment with liraglutide for twelve months on top of rennin-angiotensin system blockers led to a significant reduction in $\mathrm{HbA1c}$, proteinuria and counteracted the progression of diabetic

Published by Bioscientifica Ltd 
nephropathy as indicated by decreasing the rate of decline in eGFR (Imamura et al. 2013). Also, another small placebo-controlled randomized trial reported that liraglutide was able to show renal beneficial effects in terms of reduction of urinary albumin excretion in type 2 diabetic patients with albuminuria (von Scholten et al. 2016). Moreover, eGFR was not affected but UACR was decreased by dulaglutide treatment in 6005 type 2 diabetic patients (Tuttle et al. 2016). Recently, the Liraglutide Effect and Action in Diabetes: Evaluation of Cardiovascular Outcome Results (LEADER) clinical trial was completed. It was revealed that the incidence of nephropathy events in type 2 diabetic patients was lower in the liraglutide group vs the placebo group; however the authors were uncertain whether this result relates to the direct renal effects of liraglutide, highlighting the need for more controlled clinical trials investigating the renal effects of GLP-1 analogues (Marso et al. 2016).

\section{SDF-1a}

SDF-1, also known as CXCL12, is a chemokine which is widely expressed in many organs. SDF-1 has six isoforms which are formed by mRNA splicing. SDF-1a is the predominant isoform and cleaved and inactivated by DPP-4. It can exert many biological actions through two chemokine receptors, CXCR4 and CXCR7. SDF-1 is known to be involved in tissue repair by enhancing the migration of endothelial progenitor cells to sites of acute injury such as ischaemia (Mulvihill \& Drucker 2014). It was reported that podocytes of $d b / d b$ mice produced SDF-1a, which augmented proteinuria and glomerulosclerosis, while using the SDF-1 specific inhibitor NOX-A12 corrected glomerulosclerosis, enhanced the number of podocytes, maintained the peritubular vasculature and delayed the onset of albuminuria (Sayyed et al. 2009). In contrast, decreased endothelial SDF-1a was accompanied by proteinuria, enhanced oxidative stress, podocyte foot process effacement and increased glomerular size in Zucker obese rats. These findings were counteracted with linagliptin treatment (Nistala et al. 2014). Moreover, (Takashima et al. 2016) used Glp1r-/- diabetic-prone Akita mice to show that linagliptin enhanced renal SDF-1 expression leading to improved renal outcomes, independent of GLP-1R signalling, which were counteracted using AMD3100, a selective SDF-1 receptor blocker. Thus the available data on SDF-1 in the setting of diabetic nephropathy remain controversial and need more investigation.

\section{Other substrates}

DPP-4 substrates include many other substrates such as glucose-dependent insulinotropic polypeptide (GIP), brain natriuretic peptide (BNP), substance $\mathrm{P}$, peptide YY and neuropeptide Y (NPY). The available literature on the renal effects of these substrates in the setting of diabetic nephropathy is still limited partially due to a lack of sensitive assays which can differentiate between cleaved and uncleaved substrates.

In summary, DPP-4 is related to pathological kidney conditions including diabetic nephropathy. DPP-4 inhibition could be a promising approach for management of diabetic nephropathy. Given the pleiotropic actions of DPP-4, due to its wide range of substrates with different biological activities, the mechanisms by which DPP-4 inhibition could attenuate kidney injury are not well defined so far. More studies are required to clarify the reno-protective mechanisms of DPP-4 inhibition and more clinical trials are needed to validate this approach.

Declaration of interest

The authors declare that there is no conflict of interest that could be perceived as prejudicing the impartiality of this review. $\mathrm{BH}$ has received research grants from Boehringer Ingelheim, the manufacturer of linagliptin.

\section{Funding}

This work did not receive any specific grant from any funding agency in the public, commercial, or not-for-profit sector.

\section{References}

Alter ML, Ott IM, von Websky K, Tsuprykov O, Sharkovska Y, KrauseRelle K, Raila J, Henze A, Klein T \& Hocher B 2012 DPP-4 inhibition on top of angiotensin receptor blockade offers a new therapeutic approach for diabetic nephropathy. Kidney and Blood Pressure Research 36 119-130. (doi:10.1159/000341487)

Chaykovska L, Alter ML, von Websky K, Hohmann M, Tsuprykov O, Reichetzeder C, Kutil B, Kraft R, Klein T \& Hocher B 2013 Effects of telmisartan and linagliptin when used in combination on blood pressure and oxidative stress in rats with 2-kidney-1-clip hypertension. Journal of Hypertension 31 2290-2298; discussion 2299. (doi:10.1097/HJH.0b013e3283649b4d)

Cooper ME, Perkovic V, Groop PH, Hocher B, Cescutti J, Meinicke T, KoitkaWeber A, Thiemann S \& von Eynatten M 2016 Abstracts of 52nd EASD annual meeting. Diabetologia 59 (Supplement 1) 1-581. (doi:10.1007/s00125-016-4046-9)

Crajoinas RO, Oricchio FT, Pessoa TD, Pacheco BP, Lessa LM, Malnic G \& Girardi AC 2011 Mechanisms mediating the diuretic and natriuretic actions of the incretin hormone glucagon-like peptide-1. American Journal of Physiology: Renal Physiology 301 F355-F363. (doi:10.1152/ajprenal.00729.2010)

Fujita H, Morii T, Fujishima H, Sato T, Shimizu T, Hosoba M, Tsukiyama K, Narita T, Takahashi T, Drucker DJ, et al. 2014a The protective roles of GLP-1R signaling in diabetic nephropathy: possible mechanism

Published by Bioscientifica Ltd. 
and therapeutic potential. Kidney International 85 579-589. (doi:10.1038/ki.2013.427)

Fujita H, Taniai H, Murayama H, Ohshiro H, Hayashi H, Sato S, Kikuchi N, Komatsu T, Komatsu K, Narita T, et al. 2014b DPP-4 inhibition with alogliptin on top of angiotensin II type 1 receptor blockade ameliorates albuminuria via up-regulation of SDF-1alpha in type 2 diabetic patients with incipient nephropathy. Endocrine Journal 61 159-166. (doi:10.1507/endocrj.EJ13-0305)

Goldshtein I, Karasik A, Melzer-Cohen C, Engel SS, Yu S, Sharon O, Brodovicz K, Gadir N, Katzeff HL, Radican L, et al. 2016 Urinary albumin excretion with sitagliptin compared to sulfonylurea as add on to metformin in type 2 diabetes patients with albuminuria: a real-world evidence study. Journal of Diabetic Complications 30 1354-1359. (doi:10.1016/j.jdiacomp.2016.05.012)

Groop PH, Cooper ME, Perkovic V, Emser A, Woerle HJ \& von Eynatten M 2013 Linagliptin lowers albuminuria on top of recommended standard treatment in patients with type 2 diabetes and renal dysfunction. Diabetes Care 36 3460-3468. (doi:10.2337/dc13-0323)

Groop PH, Cooper ME, Perkovic V, Sharma K, Schernthaner G, Haneda M, Hocher B, Gordat M, Cescutti J, Woerle HJ, et al. 2015 Dipeptidyl peptidase-4 inhibition with linagliptin and effects on hyperglycaemia and albuminuria in patients with type 2 diabetes and renal dysfunction: Rationale and design of the MARLINA-T2D trial. Diabetes and Vascular Disease Research 12 455-462. (doi:10.1177/1479164115579002)

Groop PH, Cooper ME, Perkovic V, Hocher B, Kanasaki K, Sharma K, Stanton RC, Toto R, Cescutti J, Gordat M, et al. 2016 Abstracts of 52nd EASD annual meeting. Diabetologia 59 (Supplement 1) 1-581. (doi:10.1007/s00125-016-4014-4)

Hartel S, Gossrau R, Hanski C \& Reutter W 1988 Dipeptidyl peptidase (DPP) IV in rat organs. Comparison of immunohistochemistry and activity histochemistry. Histochemistry 89 151-161. (doi:10.1007/ BF00489918)

Hattori S 2011 Sitagliptin reduces albuminuria in patients with type 2 diabetes. Endocrine Journal 58 69-73. (doi:10.1507/endocrj.K10E-382)

Hendarto H, Inoguchi T, Maeda Y, Ikeda N, Zheng J, Takei R, Yokomizo H, Hirata E, Sonoda N \& Takayanagi R 2012 GLP-1 analog liraglutide protects against oxidative stress and albuminuria in streptozotocininduced diabetic rats via protein kinase A-mediated inhibition of renal NAD(P)H oxidases. Metabolism 61 1422-1434. (doi:10.1016/j. metabol.2012.03.002)

Higashijima Y, Tanaka T, Yamaguchi J, Tanaka S \& Nangaku M 2015 Anti-inflammatory role of DPP-4 inhibitors in a nondiabetic model of glomerular injury. American Journal of Physiology: Renal Physiology 308 F878-F887. (doi:10.1152/ajprenal.00590.2014)

Hopsu-Havu VK \& Glenner GG 1966 A new dipeptide naphthylamidase hydrolyzing glycyl-prolyl-beta-naphthylamide. Histochemie $\mathbf{7}$ 197-201. (doi:10.1007/BF00577838)

Imamura S, Hirai K \& Hirai A 2013 The glucagon-like peptide-1 receptor agonist, liraglutide, attenuates the progression of overt diabetic nephropathy in type 2 diabetic patients. Tohoku Journal of Experimental Medicine 231 57-61. (doi:10.1620/tjem.231.57)

Ingelfinger JR \& Rosen CJ 2016 Cardiac and renovascular complications in type 2 diabetes - is there hope? New England Journal of Medicine 375 380-382. (doi:10.1056/NEJMe1607413)

Jackson EK, Kochanek SJ \& Gillespie DG 2012 Dipeptidyl peptidase IV regulates proliferation of preglomerular vascular smooth muscle and mesangial cells. Hypertension 60 757-764. (doi:10.1161/ HYPERTENSIONAHA.112.196501)

Jung E, Kim J, Ho Kim S, Kim S \& Cho MH 2015 Gemigliptin improves renal function and attenuates podocyte injury in mice with diabetic nephropathy. European Journal of Pharmacology 761 116-124. (doi:10.1016/j.ejphar.2015.04.055)

Kanasaki K, Shi S, Kanasaki M, He J, Nagai T, Nakamura Y, Ishigaki Y, Kitada M, Srivastava SP \& Koya D 2014 Linagliptin-mediated DPP-4 inhibition ameliorates kidney fibrosis in streptozotocin-induced diabetic mice by inhibiting endothelial-to-mesenchymal transition in a therapeutic regimen. Diabetes 63 2120-2131. (doi:10.2337/db131029)

Kettmann U, Humbel B \& Holzhausen HJ 1992 Ultrastructural localization of dipeptidylpeptidase IV in the glomerulum of the rat kidney. Acta Histochemica 92 225-227. (doi:10.1016/S00651281(11)80085-1)

Kodera R, Shikata K, Kataoka HU, Takatsuka T, Miyamoto S, Sasaki M, Kajitani N, Nishishita S, Sarai K, Hirota D, et al. 2011 Glucagon-like peptide-1 receptor agonist ameliorates renal injury through its antiinflammatory action without lowering blood glucose level in a rat model of type 1 diabetes. Diabetologia 54 965-978. (doi:10.1007/ s00125-010-2028-x)

Kodera R, Shikata K, Takatsuka T, Oda K, Miyamoto S, Kajitani N, Hirota D, Ono T, Usui HK \& Makino H 2014 Dipeptidyl peptidase-4 inhibitor ameliorates early renal injury through its antiinflammatory action in a rat model of type 1 diabetes. Biochemical and Biophysical Research Communications 443 828-833. (doi:10.1016/j. bbrc.2013.12.049)

Li W, Cui M, Wei Y, Kong X, Tang L \& Xu D 2012 Inhibition of the expression of TGF-beta1 and CTGF in human mesangial cells by exendin-4, a glucagon-like peptide-1 receptor agonist. Cellular Physiology and Biochemistry 30 749-757. (doi:10.1159/000341454)

Lim SW, Jin L, Piao SG, Chung BH \& Yang CW 2015 Inhibition of dipeptidyl peptidase IV protects tacrolimus-induced kidney injury. Laboratory Investigation 95 1174-1185. (doi:10.1038/ labinvest.2015.93)

Liu WJ, Xie SH, Liu YN, Kim W, Jin HY, Park SK, Shao YM \& Park TS 2012 Dipeptidyl peptidase IV inhibitor attenuates kidney injury in streptozotocin-induced diabetic rats. Journal of Pharmacology and Experimental Therapeutics 340 248-255. (doi:10.1124/ jpet.111.186866)

Marso SP, Daniels GH, Brown-Frandsen K, Kristensen P, Mann JF, Nauck MA, Nissen SE, Pocock S, Poulter NR, Ravn LS, et al. 2016 Liraglutide and cardiovascular outcomes in type 2 diabetes. New England Journal of Medicine 375 311-322. (doi:10.1056/NEJMoa1603827)

Matsui T, Nakashima S, Nishino Y, Ojima A, Nakamura N, Arima K, Fukami K, Okuda S \& Yamagishi S 2015 Dipeptidyl peptidase-4 deficiency protects against experimental diabetic nephropathy partly by blocking the advanced glycation end products-receptor axis. Laboratory Investigation 95 525-533. (doi:10.1038/labinvest.2015.35)

Mega C, de Lemos ET, Vala H, Fernandes R, Oliveira J, MascarenhasMelo F, Teixeira F \& Reis F 2011 Diabetic nephropathy amelioration by a low-dose sitagliptin in an animal model of type 2 diabetes (Zucker diabetic fatty rat). Experimental Diabetes Research 2011 162092. (doi:10.1155/2011/162092)

Mima A, Hiraoka-Yamomoto J, Li Q, Kitada M, Li C, Geraldes P, Matsumoto M, Mizutani K, Park K, Cahill C, et al. 2012 Protective effects of GLP-1 on glomerular endothelium and its inhibition by PKCbeta activation in diabetes. Diabetes 61 2967-2979. (doi:10.2337/ db11-1824)

Min HS, Kim JE, Lee MH, Song HK, Kang YS, Lee MJ, Lee JE, Kim HW, Cha JJ, Chung YY, et al. 2014 Dipeptidyl peptidase IV inhibitor protects against renal interstitial fibrosis in a mouse model of ureteral obstruction. Laboratory Investigation 94 598-607. (doi:10.1038/labinvest.2014.50)

Mitic B, Lazarevic G, Vlahovic P, Rajic M \& Stefanovic V 2008 Diagnostic value of the aminopeptidase N,N-acetyl-beta-Dglucosaminidase and dipeptidylpeptidase IV in evaluating tubular dysfunction in patients with glomerulopathies. Renal Failure $\mathbf{3 0}$ 896-903. (doi:10.1080/08860220802359048)

Moon JY, Woo JS, Seo JW, Lee A, Kim DJ, Kim YG, Kim SY, Lee KH, Lim SJ, Cheng XW, et al. 2016 The dose-dependent organ-specific effects of a dipeptidyl peptidase- 4 inhibitor on cardiovascular complications in a model of type 2 diabetes. PLOS ONE 11 e0150745. (doi:10.1371/ journal.pone.0150745) 
Mulvihill EE \& Drucker DJ 2014 Pharmacology, physiology, and mechanisms of action of dipeptidyl peptidase-4 inhibitors. Endocrine Reviews 35 992-1019. (doi:10.1210/er.2014-1035)

Nakashima S, Matsui T, Takeuchi M \& Yamagishi SI 2014 Linagliptin blocks renal damage in type 1 diabetic rats by suppressing advanced glycation end products-receptor axis. Hormone and Metabolic Research 46 717-721. (doi:10.1055/s-0034-1371892)

Nistala R, Habibi J, Aroor A, Sowers JR, Hayden MR, Meuth A, Knight W, Hancock T, Klein T, DeMarco VG, et al. 2014 DPP4 inhibition attenuates filtration barrier injury and oxidant stress in the zucker obese rat. Obesity 22 2172-2179. (doi:10.1002/oby.20833)

Ojima A, Ishibashi Y, Matsui T, Maeda S, Nishino Y, Takeuchi M, Fukami K \& Yamagishi S 2013 Glucagon-like peptide-1 receptor agonist inhibits asymmetric dimethylarginine generation in the kidney of streptozotocininduced diabetic rats by blocking advanced glycation end productinduced protein arginine methyltranferase-1 expression. American Journal of Pathology 182 132-141. (doi:10.1016/j.ajpath.2012.09.016)

Panchapakesan U \& Pollock CA 2014 DPP-4 inhibitors-renoprotection in diabetic nephropathy? Diabetes 63 1829-1830. (doi:10.2337/ db14-0366)

Park CW, Kim HW, Ko SH, Lim JH, Ryu GR, Chung HW, Han SW, Shin SJ, Bang BK, Breyer MD, et al. 2007 Long-term treatment of glucagon-like peptide-1 analog exendin- 4 ameliorates diabetic nephropathy through improving metabolic anomalies in $\mathrm{db} / \mathrm{db}$ mice. Journal of the American Society of Nephrology 18 1227-1238. (doi:10.1681/ASN.2006070778)

Pyke C \& Knudsen LB 2013 The glucagon-like peptide-1 receptor - or not? Endocrinology 154 4-8. (doi:10.1210/en.2012-2124)

Reichetzeder C, von Websky K, Tsuprykov O, Mohagheghi Samarin A, Falke LG, Dwi Putra SE, Hasan AA, Antonenko V, Curato C\& Rippman J, et al. 2017 Head to head comparison of structurally unrelated DPP4 inhibitors in the setting of renal ischemia reperfusion injury. British Journal of Pharmacology [in press]. (doi:10.1111/ bph.13822)

Rieg T, Gerasimova M, Murray F, Masuda T, Tang T, Rose M, Drucker DJ \& Vallon V 2012 Natriuretic effect by exendin-4, but not the DPP-4 inhibitor alogliptin, is mediated via the GLP-1 receptor and preserved in obese type 2 diabetic mice. American Journal of Physiology: Renal Physiology 303 F963-F971. (doi:10.1152/ajpcell.00217.2012)

Sakata K, Hayakawa M, Yano Y, Tamaki N, Yokota N, Eto T, Watanabe R, Hirayama N, Matsuo T, Kuroki K, et al. 2013 Efficacy of alogliptin, a dipeptidyl peptidase- 4 inhibitor, on glucose parameters, the activity of the advanced glycation end product (AGE) - receptor for AGE (RAGE) axis and albuminuria in Japanese type 2 diabetes. Diabetes/ Metabolism Research and Reviews 29 624-630. (doi:10.1002/dmrr.2437)

Sayyed SG, Hagele H, Kulkarni OP, Endlich K, Segerer S, Eulberg D, Klussmann S \& Anders HJ 2009 Podocytes produce homeostatic chemokine stromal cell-derived factor-1/CXCL12, which contributes to glomerulosclerosis, podocyte loss and albuminuria in a mouse model of type 2 diabetes. Diabetologia 52 2445-2454. (doi:10.1007/ s00125-009-1493-6)

Schlatter P, Beglinger C, Drewe J \& Gutmann H 2007 Glucagon-like peptide 1 receptor expression in primary porcine proximal tubular cells. Regulatory Peptides 141 120-128. (doi:10.1016/j. regpep.2006.12.016)

Scirica BM, Bhatt DL, Braunwald E, Steg PG, Davidson J, Hirshberg B, Ohman P, Frederich R, Wiviott SD, Hoffman EB, et al. 2013 Saxagliptin and cardiovascular outcomes in patients with type 2 diabetes mellitus. New England Journal of Medicine 369 1317-1326. (doi:10.1056/NEJMoa1307684)

Sharkovska Y, Reichetzeder C, Alter M, Tsuprykov O, Bachmann S, Secher T, Klein T \& Hocher B 2014 Blood pressure and glucose independent renoprotective effects of dipeptidyl peptidase- 4 inhibition in a mouse model of type-2 diabetic nephropathy. Journal of Hypertension 32 2211-2223; discussion 2223. (doi:10.1097/ HJH.0000000000000328)

Shi S, Srivastava SP, Kanasaki M, He J, Kitada M, Nagai T, Nitta K, Takagi S, Kanasaki K \& Koya D 2015 Interactions of DPP-4 and integrin beta1 influences endothelial-to-mesenchymal transition. Kidney International 88 479-489. (doi:10.1038/ki.2015.103)

Stange T, Kettmann U \& Holzhausen HJ 1996 Immunoelectron microscopic single and double labelling of aminopeptidase N (CD 13) and dipeptidyl peptidase IV (CD 26). Acta Histochemica 98 323-331. (doi:10.1016/S0065-1281(96)80025-0)

Takashima S, Fujita H, Fujishima H, Shimizu T, Sato T, Morii T, Tsukiyama K, Narita T, Takahashi T, Drucker DJ, et al. 2016 Stromal cell-derived factor- 1 is upregulated by dipeptidyl peptidase-4 inhibition and has protective roles in progressive diabetic nephropathy. Kidney International 90 783-796. (doi:10.1016/j.kint.2016.06.012)

Tsuprykov O, Ando R, Reichetzeder C, von Websky K, Antonenko V, Sharkovska Y, Chaykovska L, Rahnenfuhrer J, Hasan AA, Tammen $\mathrm{H}$, et al. 2016 The dipeptidyl peptidase inhibitor linagliptin and the angiotensin II receptor blocker telmisartan show renal benefit by different pathways in rats with 5/6 nephrectomy. Kidney International 89 1049-1061. (doi:10.1016/j.kint.2016.01.016)

Tuttle KR, McKinney TD, Davidson JA, Anglin G, Harper KD \& Botros FT 2016 Effects of once-weekly dulaglutide on kidney function in patients with type 2 diabetes in phase II and III clinical trials. Diabetes, Obesity and Metabolism 19 436-441. (doi:10.1111/dom.12816)

Ulmer AJ, Mattern T, Feller AC, Heymann E \& Flad HD 1990 CD26 antigen is a surface dipeptidyl peptidase IV (DPPIV) as characterized by monoclonal antibodies clone TII-19-4-7 and 4EL1C7. Scandinavian Journal of Immunology 31 429-435. (doi:10.1111/j.1365-3083.1990.tb02789.x)

Vivier I, Marguet D, Naquet P, Bonicel J, Black D, Li CX, Bernard AM, Gorvel JP \& Pierres M 1991 Evidence that thymocyte-activating molecule is mouse CD26 (dipeptidyl peptidase IV). Journal of Immunology 147 447-454.

von Scholten BJ, Persson F, Rosenlund S, Hovind P, Faber J, Hansen TW \& Rossing P 2016 The effect of liraglutide on renal function: a randomized clinical trial. Diabetes, Obesity and Metabolism 19 239-247. (doi:10.1111/dom.12808)

von Websky K, Reichetzeder C \& Hocher B 2014 Physiology and pathophysiology of incretins in the kidney. Current Opinion in Nephrology and Hypertension 23 54-60. (doi:10.1097/01. mnh.0000437542.77175.a0)

Wang Z, Grigo C, Steinbeck J, von Horsten S, Amann K \& Daniel C 2014 Soluble DPP4 originates in part from bone marrow cells and not from the kidney. Peptides 57 109-117. (doi:10.1016/j. peptides.2014.05.006)

Yang J, Campitelli J, Hu G, Lin Y, Luo J \& Xue C 2007 Increase in DPP-IV in the intestine, liver and kidney of the rat treated with high fat diet and streptozotocin. Life Science 81 272-279. (doi:10.1016/j. lfs.2007.04.040)

Yin QH, Zhang R, Li L, Wang YT, Liu JP, Zhang J, Bai L, Cheng JQ, Fu P \& Liu F 2016 Exendin-4 ameliorates lipotoxicity-induced glomerular endothelial cell injury by improving ABC transporter A1-mediated cholesterol efflux in diabetic apoE knockout mice. Journal of Biological Chemistry 291 26487-26501. (doi:10.1074/jbc. M116.730564)

Zeisberg M \& Zeisberg EM 2015 Evidence for antifibrotic incretinindependent effects of the DPP-4 inhibitor linagliptin. Kidney International 88 429-431. (doi:10.1038/ki.2015.175)

Received in final form 17 March 2017

Accepted 18 April 2017

Accepted Preprint published online 18 April 2017 http://jme.endocrinology-journals.org

DOI: 10.1530/JME-17-0005
C 2017 Society for Endocrinology Printed in Great Britain
Published by Bioscientifica Ltd 